6

\title{
Social, temporal and situational influences on meat consumption in the UK population
}

\section{Affiliations}

${ }^{1}$ Biomathematics \& Statistics Scotland, Aberdeen (UK)

2 Life Course and Population Health, The Rowett Institute, University of Aberdeen, Aberdeen (UK)

${ }^{3}$ Social, Economic and Geographical Sciences Research Group, The James Hutton Institute, Aberdeen (UK)

\section{${ }^{\star}$ Corresponding author: email and full address}

G W Horgan: graham.horgan@bioss.ac.uk Biomathematics \& Statistics Scotland, Aberdeen (UK)

\section{Other authors' emails}

andrea.scalco@abdn.ac.uk tony.craig@hutton.ac.uk stephen.whybrow@abdn.ac.uk j.macdiarmid@abdn.ac.uk 


\section{Social, temporal, and situational influences on meat 25 consumption in the UK population}

\section{Abstract}

28 The amount of meat consumed is having a negative impact on both health and the environment. This study investigated the probability of eating meat and the amount eaten at a meal within different social, temporal and situational contexts. Dietary intake data from 4day diet diaries of adults (19 years and above) taken from the UK National Diet and Nutrition Survey (2008/9-2013/14) were used for the analysis. Individual eating occasions were identified and the effects of where the food was eaten, with whom, day of the week, age and gender on the probability of eating meat and amount of meat eaten were modelled using general linear mixed models. Each factor showed distinctive effects on the probability of eating meat and the amount consumed. The amount of meat eaten was greater when eating with family members compared to when alone or with other companions. Both the probability and amount of meat eaten in a single eating occasion were higher on Sundays compared to the rest of the week. Eating out (e.g. restaurants/cafes) increased the probability of consuming meat and the amount compared to other situations (e.g. home, work). When considering the factors influencing meat consumption, attention must be paid to the effects of social, temporal, and situational factor as they all work to shape consumption behaviour. This information should be used in the design of interventions and development of policies for the most effective way to reduce meat consumption.

\section{Keywords}

47 Eating behaviour; Meat consumption; Temporal effect; Social facilitation; Situational 48 influence. 
There is rising concern about the negative impacts of a high consumption of meat products associated with health and the environment, such as the increased risk of non-communicable disease and contribution to climate change. Further, with a high demand for meat driving intensive production systems there are also concerns for animal welfare (Stehfest et al., 2009). The need to reduce meat consumption to limit global warming was highlighted in the recent Intergovernmental Panel on Climate Change as a one of the mitigation pathways (IPCC 2018). The demand for meat is high and many people enjoy eating meat, which poses a challenge of knowing how to encourage people to eat less.

For health, meat is an important source of many nutrients and there are benefits in including some in the diet where nutrient intakes can be marginal (e.g. iron, zinc and vitamin B12). Intakes however need to be in moderation since overconsumption of some meats can increase the risk of diet-related diseases. Processed meat has been associated with an increased risk of coronary heart diseases (Micha, Wallace, \& Mozaffarian, 2010; Snowdon, Phillips, \& Fraser, 1984) and risk of type 2 diabetes (Pan et al., 2011). In addition, there is strong evidence that the overconsumption of red meat can increase the risk of colon cancer and is a potential risk of other cancers (i.e. oesophagus, lung, stomach, and prostate) (World Cancer Research Fund \& American Institute for Cancer Research, 2007). For this reason, people are recommended to eat no more than $500 \mathrm{~g} /$ week of red meat and very little or no processed meat.

In terms of environmental impacts, livestock production is generally associated with having the greatest environmental impacts, including climate change, land use, water use and loss of biodiversity (Aleksandrowicz, Green, Joy, Smith, \& Haines, 2016; Clune, Crossin, \& Verghese, 2017; Hallström, Carlsson-Kanyama, \& Börjesson, 2015; Willett et al, 2019). Globally, the livestock sector accounts for about $18 \%$ of greenhouse gas emissions and about $80 \%$ of agricultural land use (Stehfest et al., 2009), therefore, a shift toward a more plant-based diet would reduce greenhouse gas emission (GHGE) from agriculture and land use. Dietary patterns have to change as technological solutions alone will be insufficient to meet GHGE reduction targets within the timeframe available to limit global warming (Bajželj et al., 2014). The degree of reduction in GHGE, however, varies depending on the composition of the whole diet and the foods switched for meat, with some studies having estimated dietary change could reduce emissions by up to about $50 \%$ from diets (Aleksandrowicz et al., 2016; Perignon, Vieux, Soler, Masset, \& Darmon, 2017).

In relation to meat, there appears to be a paradox between the awareness of negative impacts on health, environment, and animal welfare and the reluctance to reduce meat consumption (Macdiarmid, Douglas, \& Campbell, 2016). A recent 
survey carried out in 2017 reported that more UK consumers are aware of the environmental issues related to a diet high in meat compared to 2014 (31\% vs 28\%) (YouGov, \& Eating Better, 2017). Nonetheless, only 19\% in 2017 report they had reduced the amount of meat eaten in the past year. A number of barriers hamper consumers in reducing meat consumption. For instance, consumers tend to believe that not eating meat negatively compromise iron and protein intakes (Lea \& Worsley, 2001). Eating meat is also viewed by many as being pleasurable, and an important part of traditional meal patterns or a meal being incomplete without meat as the central component. Many consider that humans have evolved to consume meat and that not doing so is unnatural (Macdiarmid, Douglas, \& Campbell, 2016, Piazza et al., 2015). Some difficulties in reducing meat consumption are associated with beliefs about meat, for example Joy (2001) described the concept of carnism, where people have ideologies that create norms around eating certain animals and thereby they see it as part of normal eating habits.

\section{Factors influencing meat consumption}

The composition of meals and energy intake vary across the time of the day and days of the week. For instance, de Castro $(1987,2004)$ showed that among students, meal size tends to follow a circadian rhythm, with increasing energy intake over the day with peaks at lunch and dinner. Similarly, nutrient intakes follow a pattern across the day, with carbohydrate intake higher during breakfasts, protein higher during lunch, and fat intakes higher in the evening (de Castro, 1987). They also found there were variations in the amounts eaten each day across a week, with the amount eaten at weekends being greater than on weekdays (de Castro, 1991). This may be related to time available to eat and social context, and therefore the amount consumed. In a French sample, Ducrot et al. (2015) found that time available for eating may also be related to the amount of time for cooking and state of fatigue. This suggests that there is an important temporal dimension around eating, which may be determined by other non-food related activities. de Castro (1988) proposed that people regulate food intake by adjusting meal sizes, rather than adjusting the time interval between eating occasions. This is also related to the nature of developing habits around eating behaviours.

Since Lewin (1936) the behaviour of individuals has been studied in relation to the environment where eating occurs, showing that eating behaviours vary in relation to the situational context (e.g. eating at home or out). In the recent National Dietary and Nutrition Survey (NDNS) conducted in the UK, 96\% of the respondents reported that they had eaten out at least once during the previous month, and $43 \%$ of these reported doing so at least once or twice a week (Bates, Roberts, Lepps, and Porter, 2017). Food related decisions are largely influenced by the contextual food cues, which lead to different outcomes depending on how people process information. Dual processing theory suggests that people rely on two distinct systems to process information. The first one relies on cognitive functions and it requires the individual to consciously engage in a decision-making process, e.g. they consider the available 
information, the costs and benefits are weighed up, and the best option considered by the individual is selected. The outcome and choice will vary between people. The second system reflects the application of heuristics, which produce a decision without requiring a conscious deliberation by the individual. In comparison to the cognitive way of processing information, heuristics tend to lead to less optimal decisions, provide faster answers and require fewer cognitive resources. This appears especially true in out-of-home contexts, where decisions tend to be "spontaneous, rapid, and influenced by heuristic cues" (Cohen \& Babey, 2012, p.5) with an impact on both the kind and the amount of food consumed.

In this regard, Lachat et al. (2012) reported that eating out can be associated with higher energy intake, poor dietary quality, and increased risk of gaining weight. Nguyen and Powell (2014) and Kearney, Hulshof \& Gibney, (2001) also showed that adults with the habit of eating in fast-food and restaurants have a higher daily total energy intake and poorer dietary indicators (e.g. higher percentage of energy intake from fat and protein and lower from carbohydrates). Various factors can contribute to these effects, for instance, higher energy density of the food and larger portion sizes. However, given that heuristic processes tend to be more susceptible than the cognitive system to contextual cues, consumers' decisions in out-of-home contexts are likely to be influenced by other factors such as price, food presentation and menu design. Sobal et al. (2012) found that some consumers do perceive eating out of home as an unhealthy habit.

Moreover, social contexts can influence food choices that people make. de Castro and colleagues (de Castro, 1990; de Castro \& Brewer, 1992; de Castro \& Kreitzman, 1985) examined the social context (e.g. eating alone or in the presence of others) in which food was eaten by people. The analyses of food diaries showed that the amount of energy eaten in meals was over $75 \%$ more when people ate with other people present (de Castro \& Brewer, 1992). This effect, termed social facilitation, where people increase their intake in the presence of others, was replicated in a number of other studies (de Castro, 1990, 1991, 1994; de Castro, Brewer, Elmore, \& Orozco, 1990). With more people present the time at the table increased, which in turn increased the amount of food consumed (Cavazza, Graziani, \& Guidetti, 2011). This effect was also observed by Patel and Schlundt who concluded that the presence of others "drastically increases a person's vulnerability to increased food intake" (2001, p.116).

The power of social influence to facilitate eating behaviour can have different effects on people. In some studies, it has been reported it can override an individual's feeling of satiety, such that after a meal a person expresses regret due to overeating (Herman, Roth, \& Polivy, 2003). This effect is more evident when a person is with a familiar group of people than when surrounded by strangers. However, depending on the circumstances, social influence can work in an opposite way, suppressing eating behaviour. 
Herman (2015) recently reviewed the literature on social facilitation of eating with the intention of providing an overall explanation. The author distinguished the social facilitation effect into three phenomena. First, people eat more in groups than when alone. Herman explained this phenomenon by invoking "the expansive social meal". That is to say, individuals categorise meals eaten in groups as social meals and treat them differently from meals eaten alone (de Boer et al, 2007). Social meals are associated with socialization, which is often associated with more food available and with successive intake increment. Indeed Cavazza, Graziani, and Guidetti (2011) showed that social facilitation of eating occurs in social situations prior to eating, at the phase of ordering food. Moreover, Herman (2015) suggested that social facilitation may be a way to enhance friendship among dining companions. Second, the effects of social facilitation are greater with family members and friends than strangers. Herman explained this phenomenon in terms of self-impression management; where the presence of strangers can elicit an inhibitory response due to people's concerns with making a good impression, which do not occur with family members or friends. Finally, Herman suggested that the positive relationship between the amount of food eaten per individual and group size, referred to as "social correlation", can be explained by a deindividuation effect. This is where the more people present, the less will be the perceived focus by others about how much the individual is consuming.

It should also be noted that group norms can provide a shortcut for learning about food choices because members of the same social group are considered a reliable source of information about the appropriateness of behaviours (Higgs, 2015). The perception of belonging to the same social group appears to be important in the modelling of eating behaviour. The notion of social identity refers to the cognitive processes related to social groups membership together with an emotional value associated with that group (Tajfel \& Turner, 1986). In relation to food behaviour, this effect was demonstrated in a study by Cruwys et al. (2012) using a confederate who displayed an identity but this only influenced the eating behavoirs of those in the study who associated themsleves with this identity. This effect on eating behaviour is through the process of social comparison. Hence, the mere presence of people eating together does not guarantee either the occurrence of social facilitation or the suppression of food intake, it depends on the identity of other people. For these reasons, it is important to consider the amount eaten alone and in different social groups (e.g. with friends, family members, or colleagues).

Most of the work exploring social and situational influences on eating behaviours has focused on energy intakes. There is very little literature on the effect on meat consumption. As described above, ways to encourage people to eat less meat, not only for health but environmental reason, need to be found and this requires a better understanding of the social, situational, and temporal contexts in which meat is eaten. The aim of this study is to assess whether the variation in energy intakes in different contexts are seen with eating meat. 
217 Meat consumption was modelled using data from adults ( $\geq 19$ years) from self-

218 reported dietary intakes (four-day diet diary) used in the UK NDNS (Bates et al.,

219 2014; Bates et al., 2016). These data cover a 6-year period from 2008 to 2014, with

2204156 individuals recorded. The NDNS is a survey of the food consumption, nutrient

221

222

223

224

225

226

227

228

229

230

231

232

233

234

235

236

237

238

239

240

241

242

243

244

245

246

247

248

249

250

251

252 intakes and nutritional status of people aged 1.5 years and older living in private households. A representative sample is drawn from people living in the UK using postcodes. Adults are asked to record everything that they eat and drink over four consecutive day in a food diary. Food and drink consumed are not weighed, rather amounts are estimated using household measures or weights from packaging. They are also asked to provide recipes for composite dishes prepared at home. Each item of food or drink consumed is recorded, as well as the time it was eaten, where the meal was eaten and in what company. The number of other people present was not reported.

\section{Eating episodes}

There is not an agreed methodology for differentiating eating episodes (e.g. meals and snacks): the literature reports numerous different ways, including "traditional" meal patterns and varying the minimum time between separate episodes (Leech, Worsley, Timperio, \& McNaughton, 2015). In this research, an eating episode was defined as any intake recorded where the interval between eating was greater than 30 minutes (Whybrow \& Kirk, 1997), and which provided at least 50kcal (Gibney \& Wolever 1997), to exclude occasions that were mainly drinks, such as coffee or tea.

For each eating episode, the amount of meat eaten was estimated, which included beef, lamb, pork, processed red meat, other red meat, burgers, sausages, offal, poultry, processed poultry, and game birds. As little meat was recorded as being consumed between $12 \mathrm{am}$ and $6 \mathrm{am}$ ( $0.4 \%$ of all meat consumed), this time period was excluded from the analysis.

The amount of meat per eating episode had a bimodal distribution, with $79.5 \%$ of episodes containing no meat, and peaks of meat consumption midday and in the evening. The probability that an episode includes some meat in an eating episode was modelled, and then the amount of meat in grams contained when an eating episode contained meat. Exploratory data analysis indicated that the patterns were different at different times of day, and so the intake at each hour from 6am to $11 \mathrm{pm}$ was separately modelled. Fitting of models covering all times and requiring interactions between factors of interest and hour showed indications of instability (such as slow convergence or failure to converge, unusual parameter estimates with large standard errors, etc.). This was due to the large numbers of additional effects 
and interactions, each with many levels, being required. For this reason, separate models were fitted for each hour.

\section{Statistical methods}

Generalized linear mixed models (Pinheiro \& Bates, 2000) were used to model the probability of meat being included in an eating episode, since there were multiple observations for each individual, with explanatory factors varying both between and within individuals. Fixed effects were age $(<30,30$ to 40,40 to 50,50 to 60,60 to 70 and $>70 \mathrm{yrs}$ ), gender, day of the week, where the eating episode occurred, and who was present. The locations were combined into four groups: home, restaurant / café, work / college and other. The effect of social facilitation was based on who was present, and it was combined into five groups: alone, family, friends, colleagues and other. Individual ID was included as a random effect. Significance was assessed by Wald tests. As this was a large dataset, main effects tended to be significant at most times, and so all were included in every model. In most cases, two-way interactions were not significant, and any multiple testing adjustments would remove most scattered cases of significance at $5 \%$. A few cases where interactions are clearly significant with lower $p$-values, or maintained over more than one time period, are reported in the results. Effects were estimated as odds ratios relative to, or difference from, reference levels for the factors, which were Monday for day of the week, female for gender, under 30 for age group, home for location and alone for who was present.

To model the amount of meat recorded when this was non-zero, linear mixed models were used for the continuously distributed response. This was replicated for the total amount of meat (including no meat) in order to display the combined effects of the two stages.

All models were fitted using the Ime4 1.1-8 package (Douglas, Maechler, Bolker, \& Walker, 2015) in R version 3.2 (R Development Core Team, 2008).

\section{Results}

Table 1 shows the mean total amount of meat eaten $(\mathrm{g})$ during three-time intervals by gender, age and the main factors examined. Men eat more meat than women, with the difference increasing throughout the day. Age group has smaller effects, and the most notable feature of the pattern is a lower amount of meat at most times in the oldest age group, though greater at lunchtime. 
Table 1

288 Mean (SE) total amount of meat (in grams) per eating occasion at three times of the 289 day by gender and other factors.

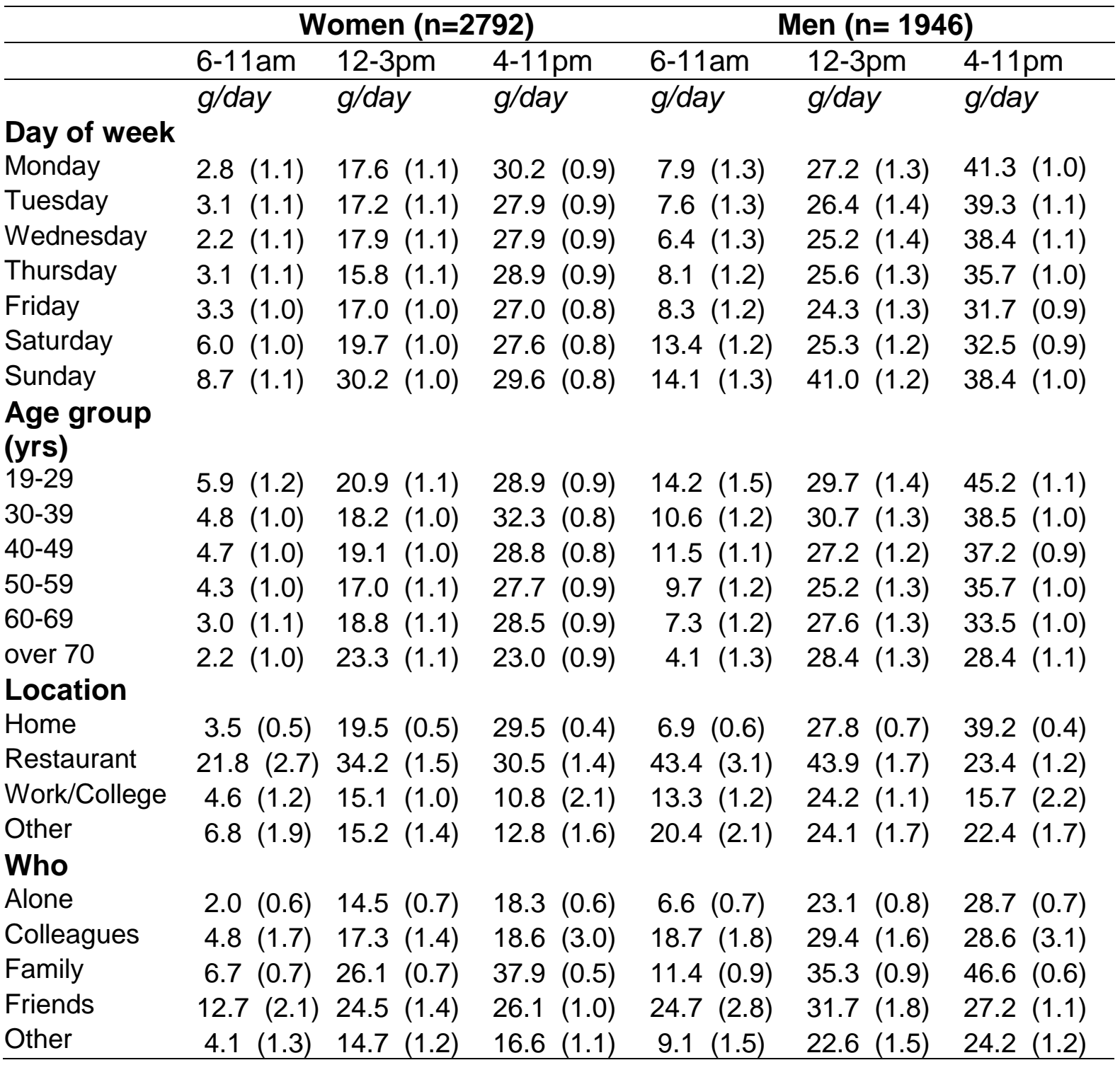

291 Figure 1 shows the overall probability of including meat in an eating episode for 292 every hour from 6am to $11 \mathrm{pm}$. There are clearly two peaks per day, with no 293 indication of one at breakfast time. The probability of including meat is only a little 294 higher in the evening than in the middle of the day, but the amount of meat included 295 increases from 15:00, and is more than 50\% higher on average than when eaten 296 earlier in the day. At a population level the probability and amount combined give the 297 overall amount during the day, the evening peak is considerably higher than the one 298 in the middle of the day. Not everyone, however, showed these two peaks. 
Figure 2 shows the effect of the situational and social context on the probability of including meat. These factors are the location and people present at the eating occasion and the day of the week. The effects are shown in three ways: the probability of meat being included (top row), the amount of meat when it is included (middle row), and the amount of meat including zero meat (bottom row), which is a combination of the first two.

All reported effects for each factor have been adjusted for any imbalance in the other factors. So, the effect of eating in a restaurant is the estimate of this effect alone, and is not due to, for example, any tendency to eat in restaurants more often at weekends, or by different age groups.

\section{--- INSERT FIGURE 2 ----}

\section{Social facilitation effect}

Eating with others increases the probability of including meat (Figure 2, top row). Note that some of the large fluctuations in some parts are not statistically significant (see supplemental tables). When eating with colleagues there is a higher chance of eating meat in the evening compared to when eating alone; on the contrary, the likelihood to consume meat when friends are present spikes in the morning and decreased during the day with a relatively small peak in the evening compared to eating alone.

Looking at the amount of meat eaten when meat is included (middle row), eating in company tends to increase the intake. Moreover, eating with others is generally associated with greater meat consumption when compared with eating alone (bottom row). In particular, eating with the family showed the greatest amount of meat consumed compared to eating alone or with other companions.

\section{Effect of the day of the week}

There were not many differences found among the weekdays Monday to Friday, but different patterns were seen on Saturdays and Sundays. At weekends, meat was more likely to be eaten in the morning. On Sundays there was a greater probability of meat being eaten at lunchtime, with a smaller increase also apparent on Saturdays (Figure 2, top row). The strongest effect of day of the week was on Sundays, where the amount was typically about $20 \mathrm{~g}$ more when compared to Monday, though this disappeared in the evening (middle row). Finally, there is a clear effect of greater meat consumption on a Sunday, and also to a much smaller extent, on a Saturday (bottom row). 
337 The effect of location is strongest at breakfast (Figure 2, top row), with eating in a 338 restaurant/café greatly increasing the probability of including meat. A smaller effect 339 can be seen at work/college. Looking at the amount of meat eaten when included in 340 a meal (middle row), this is likely to be greater in a restaurant/café, though eating in

341 other places out of the home tends to reduce the amount of meat included, apart

342 from at breakfast. Finally, the bottom row of Figure 2 shows a pattern of greater meat 343 consumption in restaurants/cafes until 16:00, and reduced consumption from 17:00 344 to 19:00. However, if occasions consisting mainly of consuming alcohol are omitted, 345 this dip in evening meat consumption largely disappears.

\section{Interactions}

347 There were very few two-way interactions between the factors. A full table of 348 interaction term odds ratios, and for coefficients for amount of meat when meat was 349 included is given in the supplementary tables.

350 The most notable interaction was related to the odds ratios for the interaction of being in a restaurant and being with friends, which indicates that two influences, both of which increase the probability of meat consumption, do not necessarily combine to produce an even greater effect. Either by itself is enough to increase the probability of meat consumption.

There were also interaction terms with covariates age and gender. Eating in a restaurant between 12:00 and 13:00 had less effect in increasing the probability of eating meat among older age groups than among 19-30 year olds. The effect of being male appears less in older age groups. The effect of eating in a restaurant appears less in males than females.

It should be noted that the NDNS data had only basic demographic information about the participants, which meant it was not possible to account for the effect and interaction of individual characteristics other than age group and gender. Including a factor for living-alone, there was no indication that this had any clear effect, or interaction with location or situational effects, on the patterns found. Statistical power may be limited however, and such influences may still occur.

To compare the patterns observed with eating meat, the total energy intake was

368 modelled in the same way (Figure S1 in supplemental materials). The same patterns 369 were observed for energy consumption as found with meat consumption, with 370 greater intake at weekends, particularly Sunday, and greater intake when eating out 371 in restaurants or with others. 


\section{Discussion}

373

374

375

376

377

378

379

380

381

382

383

384

385

386

387

388

389

390

391

392

393

394

395

396

397

398

399

400

401

402

403

404

405

406

407

408

409

This study has shown that social and situational factors influence the probability of consuming meat and the amount of meat consumed in a meal in the UK population. Time of the day, and day of the week also showed distinctive effects on meat consumption independent from eating location or with whom they ate.

\section{Social and situational context around eating meat}

The results showed that a greater amount and probability of eating meat, and a greater amount is consumed, when eating with other people compared to when alone. The effect was stronger when in the presence of family members or friends compared to colleagues, independent from the situational context or the time of the day. This finding is in accordance with previous research on social facilitation effects related to energy intakes (de Castro, 1990, 1991, 1994; de Castro \& Brewer, 1992) and the observation is consistent with the explanation of a social facilitation effect proposed by de Boer, Hoogland, and Boersema (2007) and Herman (2015).

Accordingly, the presence of other people during a meal should be considered in the development of strategies aimed at reducing meat consumption. For instance, given that the social facilitation of eating begins prior to eating food (Cavazza, Graziani, \& Guidetti, 2011), there is the possibility that a meat-eater may be influenced by their companions towards vegetarian alternatives when ordering food in the presence of others selecting a meat-free option. An increased availability of vegetarian meals to share rather than individual dishes could lead a meat-eater towards a meat-free option by the influence exerted by those who wish a to-share food option. There could also be a price incentive. Some fast-food restaurants including McDonalds and KFC sell ready-to-share meals targeted at friends or families by keeping the cost of the combined meal lower than the sum of the single products. Similar offers with vegetarian food could be constructed for sale in supermarkets or in out-of-home businesses to drive groups of consumers toward meals with less meat (Harris, \& Blair, 2006; Carroll, Samek, \& Zepeda, 2018).

\section{Meat consumption across the day and week}

Results showed that the overall amount of meat eaten during the day follows a circadian rhythm, with two spikes at midday and in the evening. Previous research showed similar energy and nutrient intake patterns (de Castro, 1987, 2004). Moreover, the analysis showed that while during the weekdays the probability of consuming meat remains relatively stable, it spikes at the weekend. This is in accordance with a previous research showing that, in UK, emphasis on meat tends to increase at weekends compared to weekdays (Marshall, 2005). Following the study by Ducrot and colleagues (2015), different reasons might drive food choices between weekdays and weekends: for instance, the time available for eating. Further 
410 research is required to investigate the reasons that drive food choices across the

411 days of the week.

412 The analysis reported in this paper showed probability of meat consumption on

413 Monday appears slightly higher than the other weekdays, but lower than Sundays.

414 This result is important as it provides some useful insights for promoting a reduction

415 of meat consumption. In fact, some health and environmental campaigns such as

416 Meatless Monday (www.meatlessmonday.com) or Meat Free Monday

417 (www.meatfreemondays.com) proposed the beginning of the week as the most

418 suitable day to reduce meat consumption. Their choice appears to be informed by

419 the fact that healthy commitments vary over the week, and are greatest at the start of

420 the week (Ayers, Althouse, Johnson, Dredze, \& Cohen, 2014). Our findings suggest

421 that Sundays more so than Mondays could be a time to reduce the amount of meat

422 consumed individually. However, this would need to consider social aspects of

423 eating, which may be more salient at the weekend. At the population level therefore,

424 Sunday rather Monday may be less effective overall with fewer people engaging with

425 it at the weekend.

The effect of eating out of the home

427

428

429

430

431

432

433

434

435

436

437

438

439

440

441

442

443

444

445

446

447

448

449

The situational context also appears to affect meat consumption. The results showed that eating in restaurants is associated with an increase in the likelihood of eating meat compared to eating at home (especially at breakfast). This appears in line with consumption trends, for instance, the last report by Food Standards Scotland (2018) reported beef burger and meat-based dishes among the top five categories of food purchased out-of-home. Moreover, the analysis showed that the amount of meat is higher when eating in restaurants than at home, consistent with evidence that restaurants tend to serve large portions (McCrory, Fuss, Saltzman, \& Roberts, 2000).

Even if the amount at the individual level appears relatively small, it is important to consider such changes at the population level. Accordingly, some interventions with food services could be useful to lower meat consumption. Working on the architecture of choices could lead to a reduction in preferences of meat consumers when eating out-of-home. This includes increasing the availability and visibility of particular foods, providing disclosures in the menu (such as the number of calories in each dish or in the case of meat the environmental impact), offering meat substitutes/meat-free products, reducing portions, increasing the ease of choice (e.g. highlighting breakfast meals without meat within the menu), or altering the order of placement of products (Bianchi, Garnett, Dorsel, Aveyard, \& Jebb, 2017).

Another out-of-home setting could be workplaces, where an intervention to reduce meat consumption could be to limit the availability of meat products. This could be a strategy to establish eating norms towards less meat among co-workers, so that eating habits persist in all those situations where colleagues are present, and 
potentially into other social settings. Social norm messages have been proven to be a useful leverage to alter eating norms via social influence (Higgs, 2015; Robinson, Fleming, \& Higgs, 2014; Stea, \& Pickering, 2018; Stok, De Ridder, De Vet, \& De Wit, 2014). For instance, Thomas et al. (2017) showed the power of norm-based messages on altering food choices in a workplace restaurant. A poster stressing that most people eat vegetables with their meal was associated with an increase in the preference for meals with vegetables compared to a baseline period. Interestingly, the influence of the message on purchasing behaviour persisted after the removal of the poster. Nevertheless, the persistence of such influence outside working context requires further research.

460 Strategies aimed at changing consumption at the individual level should be complemented by interventions to guide collectives of consumers towards more sustainable practices. At the individual level, nudge theory provides a set of tools useful to steer consumer behaviour towards healthier and more sustainable habits by restructuring the environment at the retail level (Bianchi et al, 2017). In addition, social marketing campaigns at the national level appear to be a necessary action to produce a change in consumer behaviours. Robinson et al. (2014) showed that a message that included references to social norms had more effect in increasing fruit and vegetable intake than educational health messages. Accordingly, rather than relying on an educational paradigm, a variety of nudges (Sunstein, 2016) could be employed in social marketing campaigns to increase the effectiveness of such interventions. In particular, nudges based on normative influence (i.e. suggesting that others perform the desired behaviour) have been shown to be effective on changing eating behaviour. Stea and Pickering (2017) showed that the use of a message built around social norms was positively associated with a reduction in the intention to consume red meat. Alternative nudges used in the development of a persuasive message could for example employ graphic warnings, use a simpler language, or elicit commitments and raise a sense of responsibility (e.g. "Do you plan to reduce your consumption of meat?").

However, interventions at the social level should also be planned to assure individual changes will be sustained in everyday practices (Sahakian \& Wilhite, 2014). There is still some lack of awareness of some of the environmental issues caused by meat consumption by UK consumers (Macdiarmid, Douglas, \& Campbell, 2016) and actions conducted at the collective level could be beneficial in increasing the awareness and sustain changes at the individual level. Meat consumption is associated with strong personal influences and preferences and therefore these too would need to be considered.

\section{Limitations and future research}

488 It is likely that some aspects of the influences on meat consumption were not 489 captured by the data. The number of people present during the meal was unknown, 490 which can affect the intake (de Castro, \& Brewer, 1992). Gender of those present 
491

492

493

494

495

496

497

498

499

500

501

502

503

504

505

506

507

508

509

510

511

512

513

514

515

\section{$516 \quad$ Funding}

517 This work was supported by The Scottish Government's Rural and Environment Science and 518 Analytical Services Division (RESAS).

was also not reported, nor what they ate. When participants ate in restaurants, the specific type of establishment remained unknown. It is plausible that choices about meat differ depending on whether they are made in a fast food outlet or restaurant that may provide more options. The dietary data were self-reported and this could introduce issues associated with mis-reporting of food intakes, and underestimate consumption of foods (de Castro, 1988).

Finally, given the absence of a unique definition of meal, the analysis in this study was based on previous works (Gibney \& Wolever 1997; Whybrow \& Kirk, 1997), which defined an eating episode to a minimum time period and number of calories eaten. However, different definitions could be applied for differentiating eating episodes. While the current research looked at the meat content in terms of eating occasions, further research needs to understand what influences the choice of the context, time, and companions of such eating occasions.

\section{Conclusion}

In summary, this study showed that both situational and social factors play an important role in shaping consumers' likelihood to consume meat and the amount of meat intake. Despite the difference in meat consumption being modest at the individual level, when they are scaled up to the population level then substantial changes are likely to emerge, which would be beneficial for reducing GHGE. However, the analyses conducted here captured and modelled only a small part of the totality of factors influencing eating behaviour, and how this relates to the consumption of meat. The present model is conditional on the eating occasions given, although clearly decisions are made by each person on when to eat, and what to eat. The design of future interventions and policies to reduce meat consumption need to incorporate the effects of where a meal is eaten, with whom, and when. 
521

522

523

524

525

526

527

528

529

530

531

532

533

534

535

536

537

538

539

540

541

542

543

544

545

546

547

548

549

550

551

552

553

554

555

556

557

558

559

560

Aleksandrowicz, L., Green, R., Joy, E. J. M., Smith, P., \& Haines, A. (2016). The impacts of dietary change on greenhouse gas emissions, land use, water use, and health: A systematic review. Plos One, 11(11), e0165797. https://doi.org/10.1371/journal.pone.0165797.

Ayers, J. W., Althouse, B. M., Johnson, M., Dredze, M., \& Cohen, J. E. (2014). What's the healthiest day? Circaseptan (weekly) rhythms in healthy considerations. American Journal of Preventive Medicine, 47(1), 73-76. https://doi.org/10.1016/j.amepre.2014.02.003

Bajželj, B., Richards, K. S., Allwood, J. M., Smith, P., Dennis, J. S., Curmi, E., \& Gilligan, C. A. (2014). Importance of food-demand management for climate mitigation. Nature Climate Change, 4(10), 924-929. https://doi.org/10.1038/nclimate2353.

Bates, B., Cox, L., Nicholson, S., Page, P., Prentice, A., Steer, T., \& Swan, G. (2016). National Diet and Nutrition Survey Results from Years 5 and 6 (combined) of the Rolling Programme (2012/2013-2013/2014). London, UK: Publich Health England. Retrieved from https://www.gov.uk/government/statistics/ndns-results-from-years-5-and-6combined.

Bates, B., Lennox, A., Prentice, A., Bates, C., Page, P., Nicholson, S., \& Swan, G. (2014). National Diet and Nutrition Survey: Results from Years 1, 2, 3 and 4 (combined) of the Rolling Programme (2008/2009 - 2011/2012). London, UK.: Publich Health England. Retrieved from https://www.gov.uk/government/statistics/national-diet-and-nutrition-surveyresults-from-years-1-to-4-combined-of-the-rolling-programme-for-2008-and2009-to-2011-and-2012.

Bates, B., Roberts, C., Lepps, H., \& Porter, L. (2017). The Food \& You Survey Wave 4. Retrieved from https://www.food.gov.uk/research/food-and-you/food-and-youwave-four

Bianchi, F., Garnett, E., Dorsel, C., Aveyard, P., \& Jebb, S. A. (2018). Restructuring physical micro-environments to reduce the demand for meat: A systematic review and qualitative comparative analysis. The Lancet Planetary Health, 2(9), e384-e397. https://doi.org/10.1016/S2542-5196(18)30188-8.

Carroll, K. A., Samek, A., \& Zepeda, L. (2018). Food bundling as a health nudge: Investigating consumer fruit and vegetable selection using behavioral economics. Appetite, 121, 237-248. https://doi.org/10.1016/j.appet.2017.11.082.

Cavazza, N., Graziani, A. R., \& Guidetti, M. (2011). Looking for the "right" amount to eat at the restaurant: Social influence effects when ordering. Social Influence, 6(4), 274-290. https://doi.org/10.1080/15534510.2011.632130

Clune, S., Crossin, E., \& Verghese, K. (2017). Systematic review of greenhouse gas emissions for different fresh food categories. Journal of Cleaner Production, 
Cruwys, T., Platow, M. J., Angullia, S. A., Chang, J. M., Diler, S. E., Kirchner, J. L., Wadley, A. L. (2012). Modeling of food intake is moderated by salient psychological group membership. Appetite, 58(2), 754-757.

564 https://doi.org/10.1016/j.appet.2011.12.002

D'Silva, J. (2006). Adverse impact of industrial animal agriculture on the health and welfare of farmed animals. Integrative Zoology, 1(1), 53-58. https://doi.org/10.1111/j.1749-4877.2006.00013.x

de Boer, J., Hoogland, C.T., \& Boersema, J.J. (2007). Towards more sustainable food choices: value priorities and motivational orientations. Food Quality and Preference, 18, 985-996. https://doi.org/10.1016/j.foodqual.2007.04.002

de Castro, J. M. (1987). Circadian rhythms of the spontaneous meal pattern, macronutrient intake, and mood of humans. Physiology and Behavior, 40(4), 437-446. https://doi.org/10.1016/0031-9384(87)90028-X

de Castro, J. M. (1988). Physiological, environmental, and subjective determinants of food intake in humans: A meal pattern analysis. Physiology and Behavior, 44(45), 651-659. https://doi.org/10.1016/0031-9384(88)90331-9

de Castro, J. M. (1990). Social facilitation of duration and size but not rate of the spontaneous meal intake of humans. Physiology and Behavior, 47(6), 11291135. https://doi.org/10.1016/0031-9384(90)90363-9

de Castro, J. M. (1991). Social facilitation of the spontaneous meal size of humans occurs on both weekdays and weekends. Physiology and Behavior, 49(6), 1289-1291. https://doi.org/10.1016/0031-9384(91)90365-U

de Castro, J. M. (1994). Family and friends produce greater social facilitation of food intake than other companions. Physiology and Behavior, 56(3), 445-455. https://doi.org/10.1016/0031-9384(94)90286-0

De Castro, J. M. (2004). The time of day of food intake influences overall intake in humans. The Journal of Nutrition, 134(1), 104-111.

589 https://doi.org/10.1093/jn/134.1.104

590

591

592

593

594

595

596

597

598

599

de Castro, J. M., \& Brewer, E. M. (1992). The amount eaten in meals by humans is a power function of the number of people present. Physiology and Behavior, 51(1), 121-125. https://doi.org/10.1016/0031-9384(92)90212-K

de Castro, J. M., \& Kreitzman, S. M. (1985). A microregulatory analysis of spontaneous human feeding patterns. Physiology and Behavior, 35(3), 329335. https://doi.org/10.1016/0031-9384(85)90304-X

de Castro, J. M., Brewer, E. M., Elmore, D. K., \& Orozco, S. (1990). Social facilitation of the spontaneous meal size of humans occurs regardless of time, place, alcohol or snacks. Appetite, 15(2), 89-101. https://doi.org/10.1016/0195$\underline{6663(90) 90042-7}$ 
DEFRA. (2011). Attitudes and behaviours around sustainable food purchasing. report (SERP 1011/10). York, UK: Department for Environment, Food and Rural Affairs. Retrieved from: https://webarchive.nationalarchives.gov.uk/search/

Douglas, B., Maechler, M., Bolker, B., Walker, S. (2015). Fitting linear mixed-effects models using Ime4. Journal of Statistical Software, 67(1), 1-48. https://doi.org/10.18637/jss.v067.i01.

Ducrot, P., Méjean, C., Allès, B., Fassier, P., Hercberg, S., \& Péneau, S. (2015). Motives for dish choices during home meal preparation: Results from a large sample of the NutriNet-Santé study. International Journal of Behavioral Nutrition and Physical Activity, 12(1), 1-12. https://doi.org/10.1186/s12966-015-0270-9

Food Standards Scotland. (2015). The Scottish Diet: It needs to change. Aberdeen, UK: Food Standards Scotland. Retrieved from http://www.foodstandards.gov.scot/

Gibney, M., \& Wolever, T. (1997). Periodicity of eating and human health: Present perspective and future directions. British Journal of Nutrition, 77(S1), S3-S5. https://doi.org/10.1079/BJN19970099

Hallström, E., Carlsson-Kanyama, A., \& Börjesson, P. (2015). Environmental impact of dietary change: A systematic review. Journal of Cleaner Production, 91, 1-11. https://doi.org/10.1016/j.jclepro.2014.12.008.

Harris, J., \& Blair, E. A. (2006). Consumer preference for product bundles: The role of reduced search costs. Journal of the Academy of Marketing Science, 34(4), 506-513. https://doi.org/10.1177/0092070306288405.

Herman, C. P. (2015). The social facilitation of eating. A review. Appetite, 86, 61-73. https://doi.org/10.1016/j.appet.2014.09.016

Herman, C. P., Roth, D. a, \& Polivy, J. (2003). Effects of the presence of others on food intake: A normative interpretation. Psychological Bulletin, 129(6), 873-86. https://doi.org/10.1037/0033-2909.129.6.873

Higgs, S. (2015). Social norms and their influence on eating behaviours. Appetite, 86, 38-44. https://doi.org/10.1016/j.appet.2014.10.021.

Intergovernmental Panel on Climate Change (IPCC) (2014). Climate Change 2014: Mitigation of Climate Change. Contribution of Working Group III to the Fifth Assessment Report of the Intergovernmental Panel on Climate Change. Edenhofer, O., R. Pichs-Madruga, Y. Sokona, E. Farahani, S. Kadner, K. Seyboth, ... J.C. Minx (Eds.)., Cambridge, UK: Cambridge University Press. https://doi.org/10.1017/CBO9781107415416.

Intergovernmental Panel on Climate Change (IPCC) (2018). Global warming of $1.5^{\circ} \mathrm{C}$. An IPCC special report on the impacts of global warming of $1.5^{\circ} \mathrm{C}$ above pre-industrial levels and related global greenhouse gas emission pathways, in the context of strengthening the global response to the threat of climate change, sustainable development, and efforts to eradicate poverty. Masson-Delmotte, V., Zhai, P., Pörtner, H. O., Roberts, D., Skea, J., Shukla, P.R. ... Zhou X. (Eds.). In 
642 Joy, M. (2001). From carnivore to carnist: Liberating the language of meat. Satya, $8(2), 26-27$.

644

Joy, M. (2009). Why we love dogs, eat pigs and wear cows: An introduction to carnism. San Francisco, CA: Conari Press.

646

647

648

649

650

651

652

653

654

655

656

657

658

659

660

661

662

663

664

665

666

667

668

669

670

671

672

673

674

675

676

677

678

679

680

681

Kearney, J., Hulshof, K., \& Gibney, M. (2001). Eating patterns - temporal distribution, converging and diverging foods, meals eaten inside and outside of the home - implications for developing FBDG. Public Health Nutrition, 4(2b), 693-698. https://doi.org/10.1079/PHN2001156

Lachat, C., Nago, E., Verstraeten, R., Roberfroid, D., Van Camp, J., \& Kolsteren, P. (2012). Eating out of home and its association with dietary intake: A systematic review of the evidence. Obesity Reviews, 13(4), 329-346. https://doi.org/10.1111/j.1467-789X.2011.00953.x

Lea, E., \& Worsley, A. (2001). Influences on meat consumption in Australia. Appetite, 36(2), 127-136. https://doi.org/10.1006/appe.2000.0386

Leech, R., Worsley, A., Timperio, A., \& McNaughton, S. (2015). Understanding meal patterns: Definitions, methodology and impact on nutrient intake and diet quality. Nutrition Research Reviews, 28(1), 1-21. https://doi.org/10.1017/S0954422414000262

Macdiarmid, J. I., Douglas, F., \& Campbell, J. (2016). Eating like there's no tomorrow: Public awareness of the environmental impact of food and reluctance to eat less meat as part of a sustainable diet. Appetite, 96, 487-493. https://doi.org/10.1016/j.appet.2015.10.011

Marshall, D. (2005). Food as ritual, routine or convention. Consumption Markets \& Culture, 8(1), 69-85. https://doi.org/10.1080/10253860500069042

McCrory, M. A., Fuss, P. J., Saltzman, E., Roberts, S. B. (2000). Dietary determinants of energy intake and weight regulation in healthy adults. The Journal of Nutrition, 130(2), 276S-279S. https://doi.org/10.1093/jn/130.2.276S

Micha, R., Wallace, S. K., \& Mozaffarian, D. (2010). Red and processed meat consumption and risk of incident coronary heart disease, stroke, and diabetes mellitus: A systematic review and meta-analysis. Circulation, 121(21), 22712283. https://doi.org/10.1161/circulationaha.109.924977

Monteiro, C. A., Pfeiler, T. M., Patterson, M. D., \& Milburn, M. A. (2017). The Carnism Inventory: Measuring the ideology of eating animals. Appetite, 113, 5162. https://doi.org/10.1016/j.appet.2017.02.011

Nguyen, B. T., \& Powell, L. M. (2014). The impact of restaurant consumption among US adults: Effects on energy and nutrient intakes. Public Health Nutrition, 17(11), 2445-2452. https://doi.org/10.1017/S1368980014001153

Pan, A., Sun, Q., Bernstein, A. M., Schulze, M. B., Manson, J. E., Willett, W. C., \& Hu, F. B. (2011). Red meat consumption and risk of type 2 diabetes: 3 cohorts of US adults and an updated meta-analysis. The American Journal of Clinical 
Patel, K. A., \& Schlundt, D. G. (2001). Impact of moods and social context on eating behavior. Appetite, 36(2), 111-118.

685

686

687

688

689

690

691

692

693

694

695

696

697

698

699

700

701

702

703

Perignon, M., Vieux, F., Soler, L. G., Masset, G., \& Darmon, N. (2017). Improving diet sustainability through evolution of food choices: Review of epidemiological studies on the environmental impact of diets. Nutrition Reviews, 75(1), 2-17.

\section{Piazza, J., Ruby, M. B., Loughnan, S., Luong, M., Kulik, J., Watkins, H. M., \&} Seigerman, M. (2015). Rationalizing meat consumption. The 4Ns. Appetite, 91, 114-128.

Pinheiro, J.C., \& Bates, D.M. (2000). Mixed-Effects Models in S and S-PLUS. New York, NY: Springer-Verlag New York. https://doi.org/10.1007/b98882

R Development Core Team (2008). R: A language and environment for statistical computing. Vienna, Austria: R Foundation for Statistical Computing.

Robinson, E., Fleming, A., \& Higgs, S. (2014). Prompting healthier eating: Testing the use of health and social norm based messages. Health Psychology, 33(9), 1057-1064. https://doi.org/10.1037/a0034213.

Roth, D. ., Herman, C. ., Polivy, J., \& Pliner, P. (2001). Self-presentational conflict in social eating situations: A normative perspective. Appetite, 36(2), 165-171. https://doi.org/10.1006/appe.2000.0388

Sahakian, M., \& Wilhite, H. (2014). Making practice theory practicable: Towards more sustainable forms of consumption. Journal of Consumer Culture, 14(1), $25-44$.

Snowdon, D. A., Phillips, R. L., \& Fraser, G. E. (1984). Meat consumption and fatal ischemic heart disease. Preventive Medicine, 13(5), 490-500.

Stea, S., \& Pickering, G. J. (2018). Optimizing Messaging to Reduce Red Meat Consumption. Environmental Communication. https://doi.org/10.1080/17524032.2017.1412994

Stehfest, E., Bouwman, L., Van Vuuren, D. P., Den Elzen, M. G. J., Eickhout, B., \& Kabat, P. (2009). Climate benefits of changing diet. Climatic Change, 95(1-2), 83-102. https://doi.org/10.1007/s10584-008-9534-6

Stok, F. M., De Ridder, D. T. D., De Vet, E., \& De Wit, J. B. F. (2014). Don't tell me what i should do, but what others do: The influence of descriptive and injunctive peer norms on fruit consumption in adolescents. British Journal of Health Psychology, 19(1), 52-64. https://doi.org/10.1111/bjhp.12030.

Sunstein, C. R. (2016). The Council of Psychological Advisers. Annual Review of Psychology, 67(1), 713-737. https://doi.org/10.1146/annurev-psych-081914$\underline{124745}$.

Tajfel, H., \& Turner, J. C. (1986). The social identity theory of intergroup behaviour. In S. Worchel \& W. G. Austin (Eds.), Psychology of intergroup relations. Chicago, IL: NelsonHall 
Thomas, J. M., Ursell, A., Robinson, E. L., Aveyard, P., Jebb, S. A., Herman, C. P., \& Higgs, S. (2017). Using a descriptive social norm to increase vegetable selection in workplace restaurant settings. Health Psychology, 36(11), 10261033. https://doi.org/10.1037/hea0000478.

Whybrow, S., \& Kirk, T. R. (1997). Nutrient intakes and snacking frequency in female students. Journal of Human Nutrition and Dietetics, 10(4), 237-244. https://doi.org/10.1046/j.1365-277X.1997.00059.x

Willett W, Rockström J, Loken B, Springmann M, Lang T, Vermeulen S, Garnett T, Tilman D, DeClerck F, Wood A, Jonell M, Clark M, Gordon LJ, Fanzo J, Hawkes C, Zurayk R, Rivera JA, De Vries W, Majele Sibanda L, Afshin A, Chaudhary A, Herrero M, Agustina R, Branca F, Lartey A, Fan S, Crona B, Fox E, Bignet V, Troell M, Lindahl T, Singh S, Cornell SE, Srinath Reddy K, Narain S, Nishtar S, Murray CJL. Food in the Anthropocene: the EAT-Lancet Commission on healthy diets from sustainable food systems.(2019) Lancet; 393(10170):447-492. https://doi.org/10.1016/S0140-6736(18)31788-4

World Cancer Research Fund, \& American Institute for Cancer Research. (2007). Food, nutrition, physical activity, and the prevention of cancer: A global perspective. Washington D.C., WA: American Institute for Cancer Research.

YouGov, \& Eating Better (2017). YouGov / Eating Better Survey Results. Retrieved from https://www.eating-better.org/uploads/Documents/2017/YouGov survey for Eating Better 2017_EatingLessMeat_W_170424.pdf 


\section{Figure captions}

745 Figure 1. Change during the day of the probability of including meat, the amount of

746 meat consumed when it is included, and the total amount of meat (including zeros)

747 Figure 2. Influences of company (relative to being alone), day of the week (relative 748 to Monday) and location (relative to home) on the inclusion of meat in the diet. The 749 top row shows the odds ratio for inclusion of meat in an eating episode, the middle 750 row shows the amount when meat is included and the bottom row shows the overall 751 amount, including zero meat.

752 
